\title{
Electron microscopy of myenteric nerves in Hirschsprung's disease and in normal bowel
}

\author{
E. R. HOWARD AND J. R. GARRETT \\ From the Departments of Surgery and Oral Pathology, King's College Hospital, London
}

SUMMARY The ultrastructure of the myenteric nerves of colon and rectum removed from 10 children with Hirschsprung's disease has been studied and compared with normal infant bowel.

Distal aganglionic (Hirschsprung) bowel often showed a rich supply of nerves within the muscle layers and there was no obvious morphological abnormality of constituent axons. The numbers of nerves diminished as more proximal parts of the bowel were examined and the fewest nerves were found where ganglia first appeared. These ganglia were similar in structure to the ganglia of normal bowel, and a striking feature of them all was the absence of collagen between constituent neuronal units. The larger nerve trunks of aganglionic bowel frequently contained myelinated axons and these have been observed within the myenteric plexus of normal rectum.

This study supports previous histochemical investigations of the nerves in bowel from patients with Hirschsprung's disease and indicates that the condition is due to a complex and variable abnormality of the arrangement of the nervous tissue of the bowel wall, involving myenteric nerves as well as ganglia.

A recent study of cholinesterase-positive and adrenergic nerves in the bowel, resected from young children, suggested that the symptoms and signs of Hirschsprung's disease were due to abnormalities in the distribution of the myenteric nerves as well as to an absence of ganglion cells (Garrett, Howard, and Nixon, 1969). It was considered that, in addition to the absence of coordinated contraction and relaxation consequent upon aganglionosis, increased numbers of cholinergic nerves in the distal aganglionic bowel cause a relative increase in its tone. Furthermore a deficiency of these nerves in the distal ganglionic bowel suggested a zone capable only of reduced motor activity. These conclusions were based on the assumption that the nerves demonstrated by histochemical techniques were functional and capable of activating the muscle of the bowel wall but it is not possible to determine the presence or absence of actual neuro-effector sites at light microscopical level.

Received for publication 10 July 1970.
In the present investigation tissues from a number of subjects included in the previous work have been examined by electron microscopy. The bowel from patients with Hirschsprung's disease has been compared with normal bowel in order to establish first the normality or abnormality of the individual axons, and second whether neuro-effector sites exist, so that the validity of the conclusions based on the histochemical observations could be assessed.

\section{Materials and Methods}

Gut resected because of Hirschsprung's disease from 10 children aged from 3 months to 2 years 10 months has been studied. Normal rectosigmoid removed for an unrelated condition from a child of 3 months was used as a control. All the above tissues were included in the histochemical study (Garrett et al, 1969). In addition, 


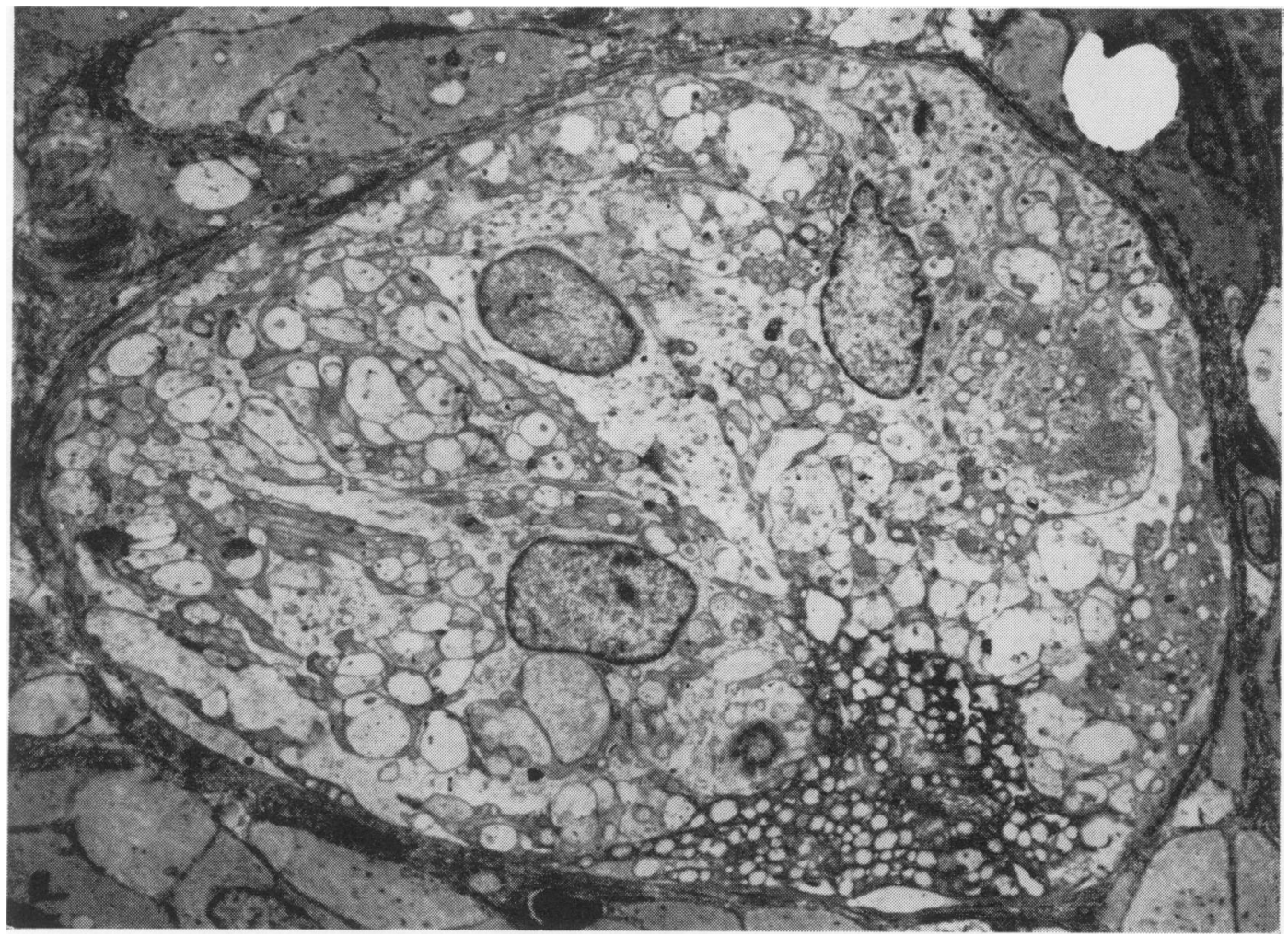

Fig. 1 Electron micrograph of ganglion in normal infant colon, stained with uranyl acetate to show collagen. Note the absence of collagen within the ganglion. $A$ 'dark' cell is present in the lower part of the ganglion $(\times 1,600)$.

because of the difficulty in obtaining further juvenile control tissue, normal rectum from two adults was examined.

Small, full-thickness strips of bowel were cut in a longitudinal direction from different levels of each resected specimen adjacent to the tissues examined in the histochemical study. The tissues were prepared as soon as the whole segment had been removed in the operating theatre. Each strip, about $2 \mathrm{~mm}$ in width, was pinned with its cut surface downwards on cork in order to minimize distortion and then immersed in fixative. Initially phosphate-buffered glutaraldehyde fixation (after the method of Sabatini, Bensch and Barrnnett, 1963) was used for four hours. Subsequently it was found that better preservation was achieved by fixing for two hours with the paraformaldehyde-glutaraldehyde mixture described by Karnovsky (1965). The tissues were washed in $0.05 \mathrm{M}$ cacodylate buffer, $p \mathrm{H} 7.2$, containing $7.5 \%$ sucrose. Each strip was then transected into small blocks less than $2 \mathrm{~mm}$ wide, postfixed in $1 \%$ osmium tetroxide, buffered with veronal acetate for two hours, dehydrated in alcohol, and embedded in Araldite. Ultra-thin sections were stained on grids with lead(Reynolds, 1963) alone or after uranyl acetate and examined in an E.M.6B electron microscope (AEI).

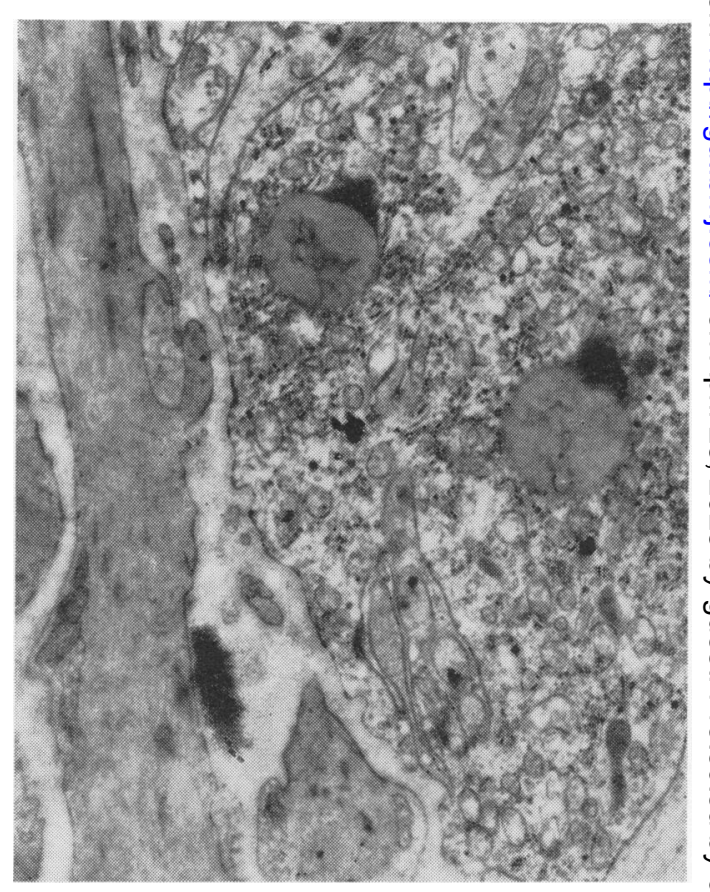

Fig. 2 Electron micrograph of normal adult rectum showing a ganglion cell in close proximity to muscle cells with a gap of about $1,500 \AA$ in places $(\times 13,000)$. 
Results in Normal Bowel

MYENTERIC GANGLIA

The ganglia were composed of extremely complicated arrangements of neurones, Schwann cells, and vast numbers of axons. The ganglionic masses were surrounded by collagen and by thin fibroblastic-like cells in a single layer which was often incomplete. Although the majority of ganglia were confined to the intermyenteric zone or submucosal regions, some were positioned partly within the layers of the longitudinal or circular muscle.

The neurones were situated at the periphery of the ganglia with much of their outer surface naked and unsupported (Figs. 1-3). This free outer surface was often relatively close to adjacent muscle cell, sometimes with a gap of less than $1 \mu$ (Fig. 2). The cytoplasm of the neurones was usually identifiable by its cytoplasmic contents which included large numbers of mitochondria, endoplasmic reticulum, and free and attached ribosomes. The preservation of mitochondria was not always good, probably as a consequence of the operative procedures. Occasional cells with a more dense cytoplasm were seen, suggesting that there may be two types of neurone but these cells usually had the least well preserved mitochondria of all.

Within the ganglia the majority of axons were between 0.4 and $1 \mu$ diameter but many were outside this range. The complexity of the arrangement of the axons and ganglion cells defies accurate description in the absence of serial reconstructions. It was impossible to define accurately the territory of each Schwann cell and usually a number of axons were present in each invagination of its plasma membrane. Sometimes the axonal contents were not well preserved. Numerous vesicles were seen but without using more specific fixation (Richardson, 1966; Hökfelt, 1967) it is not possible to make any comment on whether these were cholinergic, adrenergic, or neither. However, a fair number of large, densecored vesicles, about $1,000 \AA$ in diameter, were observed.

A characteristic of the ganglia was the almost complete absence of collagen within each ganglionic mass (Fig. 1). Another striking feature was the paucity of definitive synaptic structures with thickening of the pre- and postsynaptic membranes, although such structures were occasionally identified (Fig. 4). However, numerous examples of simple close contact between vesicle-containing axons and the plasma membranes of neurones and their processes, or with other axons, were often found and it seems possible that neurotransmission can occur at these sites.

NERVES IN THE MUSCLE LAYERS

Large numbers of non-myelinated nerves were present in the muscle layers, particularly in the circular muscle. The orientation of the axons, which ran in conjunction with Schwann cells, was similar to that of the circular and longitudinal muscle fibres. The larger bundles were usually surrounded by a layer of perineural cells but the smaller bundles were devoid of surrounding cells. Numerous individual Schwann-axon bundles, containing from one to 20 axons per Schwann cell, were found between muscle cells and occasional bare axons were seen but it was not possible to be certain that an accompanying Schwann cell had not been missed by the plane of the section. No distinct synaptic contacts were seen but axons, partially bared of Schwann cells or apparently unsupported and containing vesicles and mitochondria, were frequently found with a free surface in close proximity to a muscle cell separated by a gap of less than $500 \AA$ (Figs. 5 and 7). Such arrangements are considered to be neuro-effector sites. The adjacent muscle cells cften showed concentrations of pinocytic vesicles. The axons were not always perfectly preserved but numerous small agranular vesicles were found and there were also many large granular vesicles of diameter about $1,000 \AA$.

\section{Results in Hirschsprung's Disease}

AGANGLIONIC BOWEL

\section{Intermuscular zone}

Large nerve trunks characteristic of this condition were readily found in the intermuscular zone of all cases (Fig. 9). They were composed of hundreds of axons enclosed within a sheath of perineural cells and collagen. Smaller trunks were also present. The majority of axons were not myelinated but in six out of the 10 cases the presence of some myelinated axons was immediately apparent. The myelinated axons were between about 1.0 and $2.6 \mu$ in diameter, and were found only in the ensheathed trunks. Their ultimate destination is not known. The non-myelinated axons were usually less than $1.5 \mu$ in diameter and generally ran in groups of two to four axons per Schwann cell. Each Schwann-axon bundle was separated from its neighbour by collagen. The axons contained tubules, vesicles, and mitochondria, and showed no obvious pathological features.

Because of the somewhat unexpected finding of myelinated axons in the intermuscular zone, two necropsy specimens of normal adult rectum were specially stained for myelinated nerves. The tissues were fixed in formalin, postfixed in the osmium-tetroxide mixture, and paraffin sections were examined by light microscopy. In both specimens scattered myelinated axons were found, including occasional ones in ganglia (Fig. 10). 


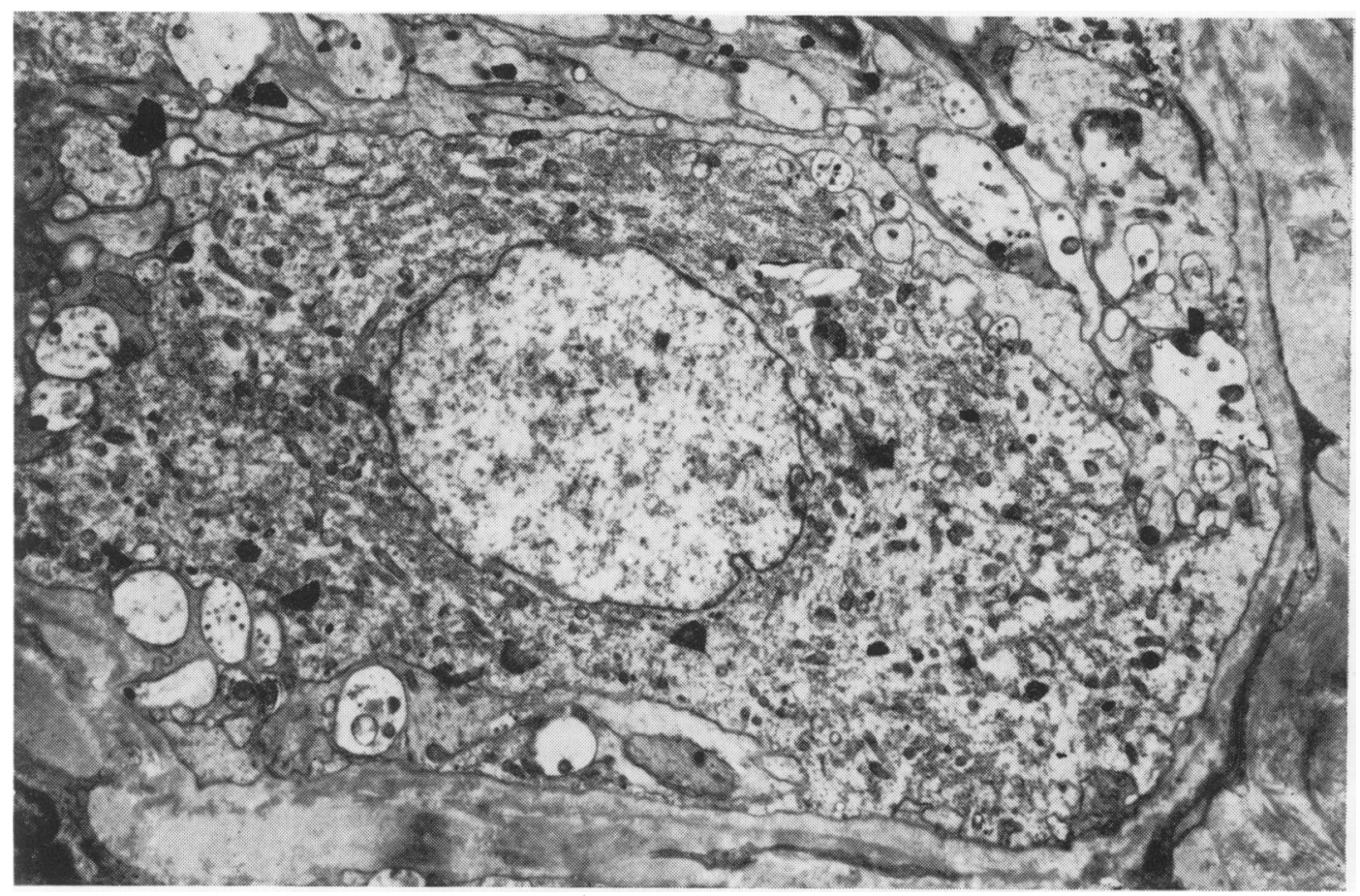

Fig. 3 Electron micrograph of ganglion in descending colon from a patient with Hirschsprung's disease showing peripheral position of a neurone $(\times 4,400)$.

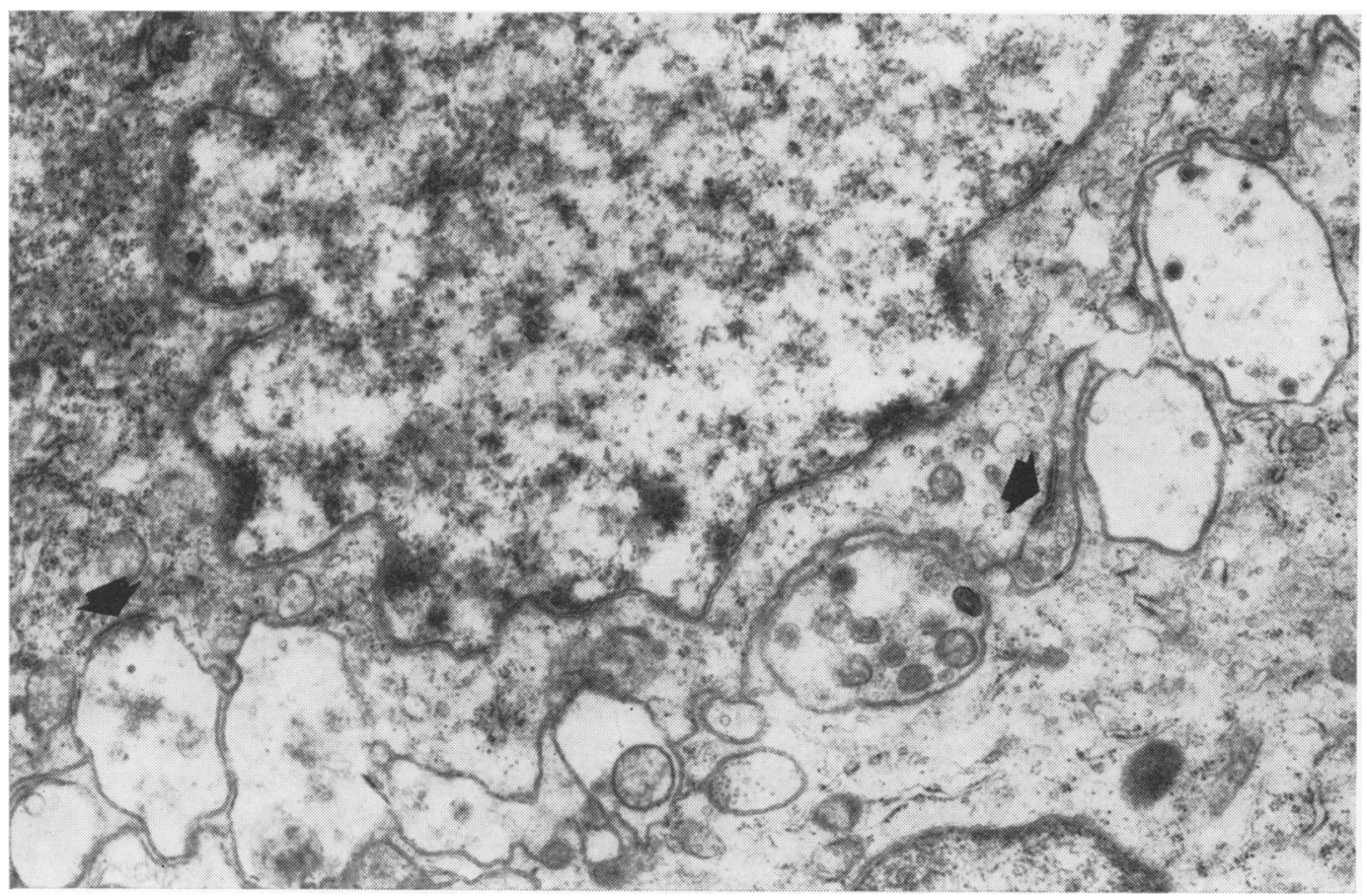

Fig. 4 Electron micrograph of ganglion in the transverse colon from a patient with Hirschsprung's disease showing two axo-somatic synapses with thickening of the synaptic membranes (arrow) $(\times 20,000)$. 
Nerves in the muscle layers

The most distal segment of aganglionic bowel in seven out of the 10 cases contained numerous non-myelinated nerves in the muscle layers, especially in the circular muscle. The nerves appeared similar to those in normal bowel and

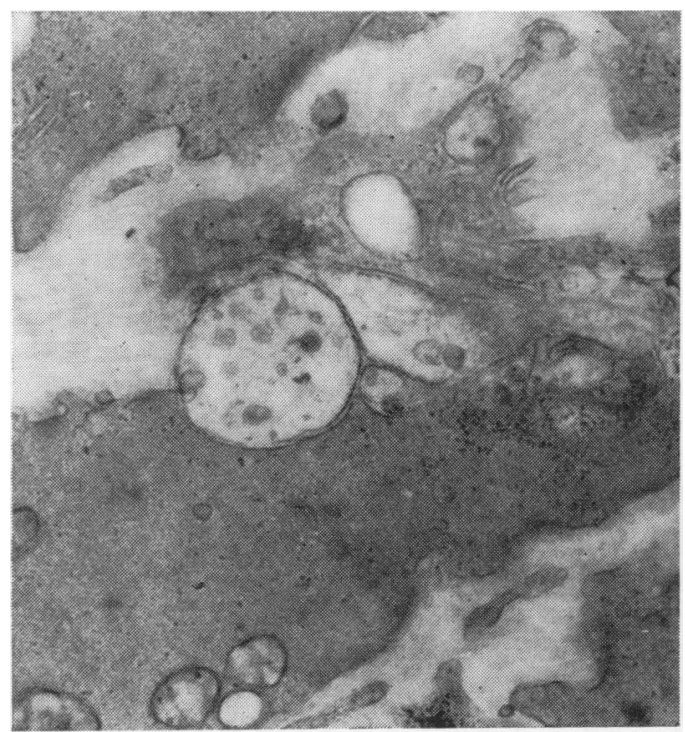

Fig. 5 Electron micrograph of normal bowel showing a vesiculated axon in very close proximity to a circular muscle cell $(\times 26,000)$.

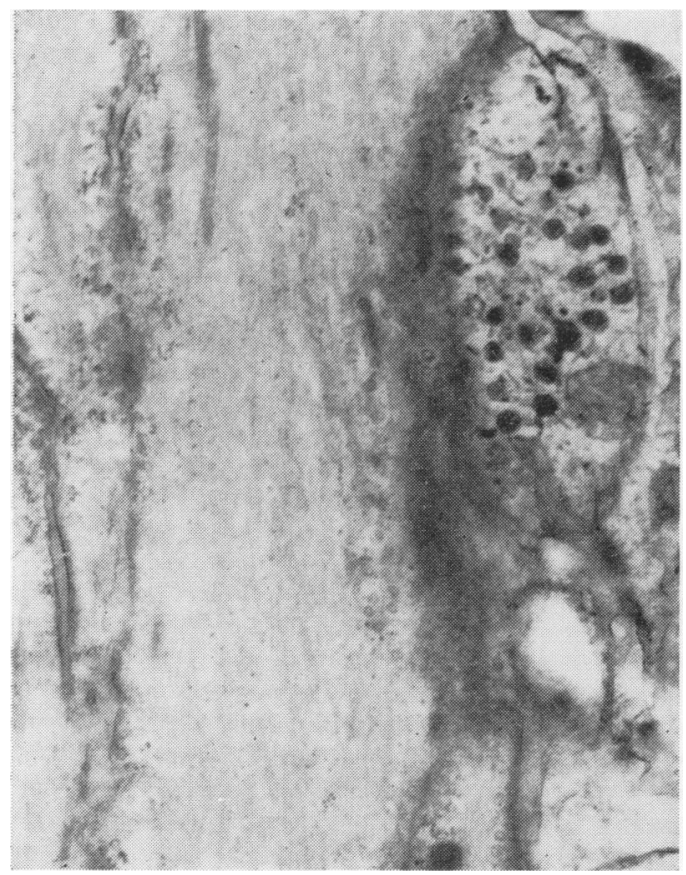

Fig. 7 Electron micrograph of normal bowel showing a vesiculated axon in very close proximity to a longitudinal muscle cell $(\times 24,000)$. showed no obvious pathological features. Sometimes there were large numbers of axons per Schwann cell but this was not markedly different from the normal. In any one section a number of nerves appeared to be in transit, for the Schwannaxon bundle was separated from the muscle

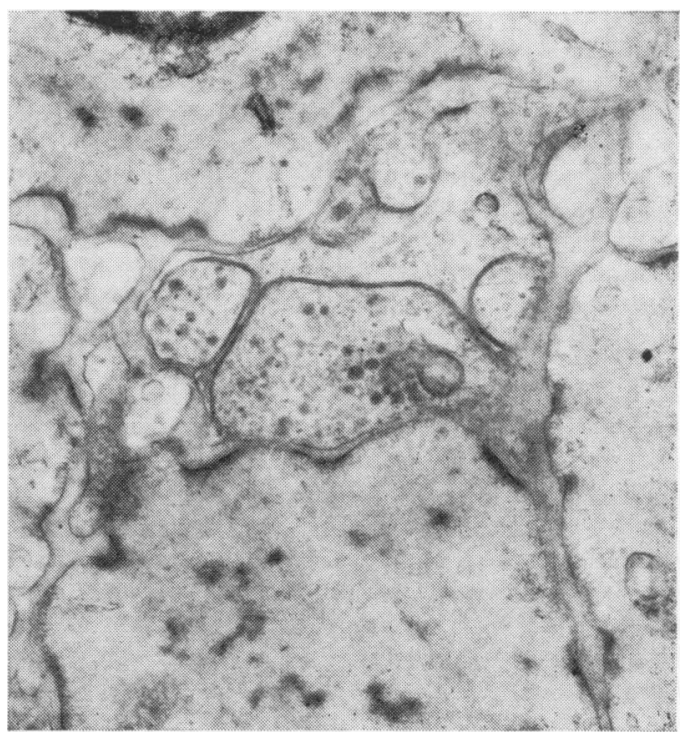

Fig. 6 Electron micrograph of aganglionic bowel showing a vesiculated axon in very close proximity to a circular muscle cell $(\times 15,000)$.

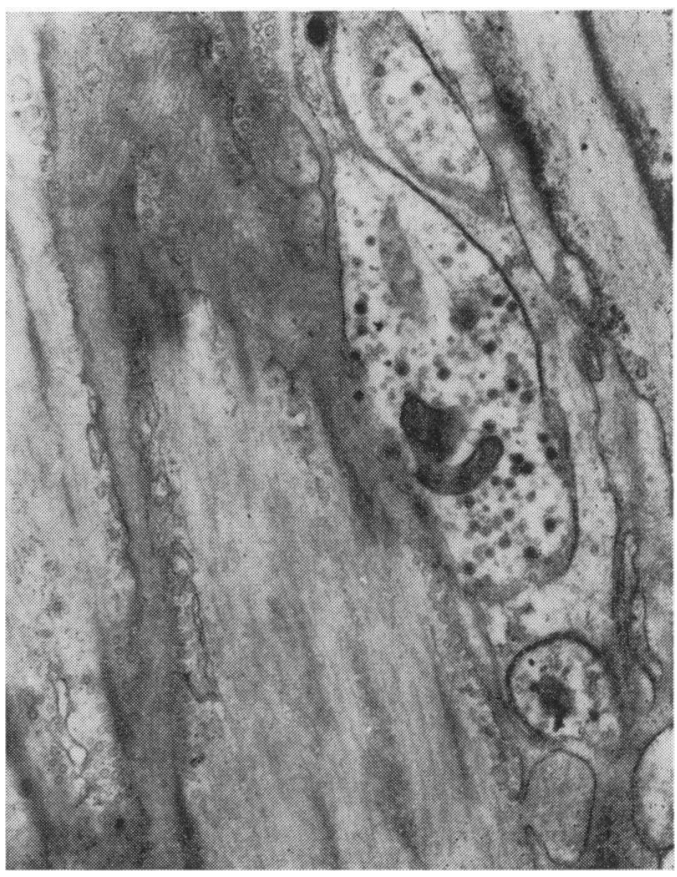

Fig. 8 Electron micrograph of aganglionic bowel showing a vesiculated axon in very close proximity to a longitudinal muscle cell $(\times 15,000)$. 
layers by a moderate amount of collagen. Numerous sites similar to those considered to be neuro-effector sites in the normal, in which an axon was in close proximity to a muscle cell with a gap of $500 \AA$ or less, were readily found (Figs. 6 and 8). In these positions the axons tended to contain increased numbers of vesicles and the muscle cell often showed concentrations of pinocytic vesicles.

As one ascended the aganglionic bowel the numbers of nerves in the circular muscle always decreased.

In the remaining three cases few nerves were found in the muscle layers at all levels of the aganglionic bowel including the most distal part. These three cases had been shown previously to possess very few cholinesterase positive or adrenergic nerves in the muscle layers (Garrett

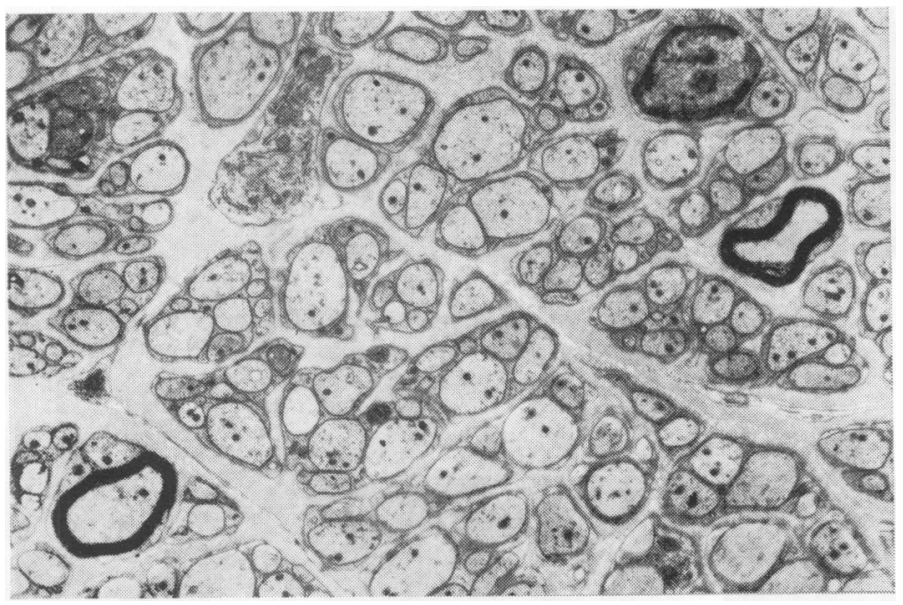

Fig. 9 Electron micrograph of part of a large nerve trunk in aganglionic bowel showing two myelinated and many unmyelinated axons $(\times 4,800)$.

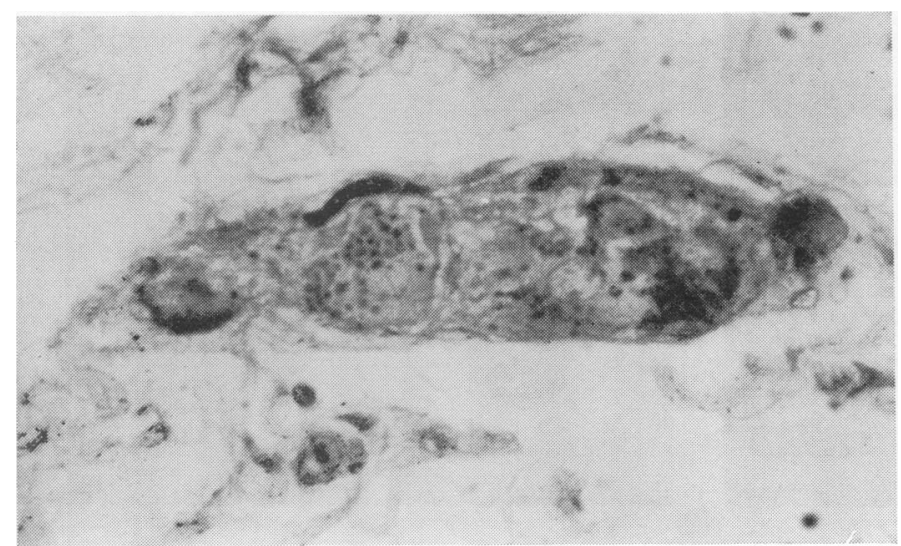

Fig. 10 Small myelinated axon within ganglion of normal adult rectum (osmium tetroxide, $\times 560$ ). et al, 1969), had presented with the mildest symptoms, and did not show contraction of the distal bowel on radiology.

GANGLIONIC BOWEL

In five of the 10 specimens ganglionic tissue from bowel proximal to the aganglionic segment was included.

\section{Ganglia}

Wherever ganglia occurred they appeared essentially similar to those in normal bowel (Figs. 3 and 4), and no obvious abnormalities were detected. The sampling error and the smallness of each sample in any electron-microscopical section makes it impossible to comment upon their relative size or frequency.

Nerves in the muscle layers

Invarably in the most distal ganglionic tissue very few muscular nerves and correspondingly few 'neuro-effector sites' were found. In two cases with more proximal ganglionic tissues the numbers of myenteric nerves and the 'neuroeffectot sites' approached normal. Thus it is concluded that a variable length of ganglionic bowel, contiguous with the aganglionic segment, has a deficient myenteric innervation.

\section{Discussion}

It should be mentioned that imperfections in the preservation of the tissues were not infrequent, the nerve tissue always being more affected than the muscle which was generally very well preserved. These defects were probably the consequence of extensive handling of the tissue and the time lag between devascularization and fixation, both of which are inevitable in operations of this nature. Sometimes there was irregular preservation within individual blocks, nevertheless sections satisfactory enough for reasonable assessment were always achieved.

The ganglia in the control tissues and those present in some proximal parts of the Hirschsprung's specimens showed great complexity. They were essentially similar to those described $\underset{\omega}{N}$ by Richardson (1958) in the small intestine of the rabbit. The absence of collagen within the ganglia $\varphi$ was totally dissimilar to the appearances within conventional autonomic ganglia, such as sym- ? pathetic ganglia in the rat (Elfvin, 1963) or 0 parasympathetic ganglia in the chorda of the cat (Garrett, 1966). In conventional autonomic ganglia each neural unit, composed of a neurone $\stackrel{\varnothing}{\propto}$ and processes, supporting cells and axons, is clearly separated from its neighbours by collagen. Human myenteric ganglia have a structure more like primitive brain tissue and it is suggested that they should be considered as a system separate 
from, but influenced by, the parasympathetic and sympathetic divisions of the autonomic system.

The peripheral distribution of the neurones with part of their outer surface unsupported is also quite distinctive. We wonder whether a similar arrangement with the free surface of neurones in close proximity to muscle cells helps to explain the proposition of Ambache and Freeman (1968), from work on the guinea-pig, that a non-cholinergic motor substance released by the ganglia reaches the muscle layers by simple diffusion. Smith (1970) describes two morphological types of myenteric neurone, and it is possible that the darker cells occasionally seen in the present study represent the argyrophilic cells described by her. However, their mitochondria were always poorly preserved and it is possible that the morphological appearances were the consequence of a metabolic catastrophe. The significance of the large granular vesicles frequently seen in axons is not understood. Their presence has been noted in Auerbach's plexus of a human embryo a mere $12 \mathrm{~mm}$ long by Kubozoe, Daikoku, and Takiti (1969), and similar vesicles have been found in both adrenergic and cholinergic axons (Hökfelt, 1966).

Although no obvious abnormalities were detected in the ganglia from proximal tissue in Hirschsprung's disease this does not necessarily imply that they can mediate normal reflex activity. It is possible that their input is impaired and certainly the innervations of the circular muscle in the most distal ganglionic bowel was always deficient.

The large nerve trunks in the intermuscular zone of the aganglionic bowel were found to be cholinesterase positive, and thus probably cholinergic, some years ago by Kamijo, Hiatt, and Koelle (1953). It is considered that they may represent nerves of the sacral parasympathetic out-flow which would normally be going to myenteric ganglia were ganglia present. Myelinated axons have not been previously observed in these nerve trunks (Bodian, 1960; Smith, 1970), although the present investigation indicates that they are probably present in a large proportion of cases. Their function is not known but since they have now been found in normal gut (Fig. 10) they may be part of an afferent system.

The numbers of nerves seen by electron microscopy in the muscle layers of bowel resected because of Hirschsprung's disease showed a close correlation with the distribution of nerves demonstrated histochemically on adjacent tissues (Garrett et al, 1969). Our conclusions based on this distribution pattern, which were summarized at the beginning of this paper, are therefore supported by the present study. On the other hand the normal bowel appeared to contain more muscular nerves than had been anticipated by the light microscopical study, and contrary to expectations there were often many axons per Schwann cell. It has already been suggested that the thicker, darker cholinesterase nerve staining often seen in the most distal aganglionic bowel was due to the presence of more axons per Schwann cell than in normal bowel, but electron microscopy does not support this idea. We would now suggest that the apparent discrepancy in nerve size may be due either to the more strongly cholinesterase-positive axons in Hirschsprung's disease, or to a proportion of the axons in normal bowel being cholinesterase negative. If the latter be true, and considering that few adrenergic nerves are present in the muscle layers (Bennett, Garrett, and Howard, 1968), is it possible that a proportion of axons in normal bowel represent a non-cholinergic, non-adrenergic system which is absent in aganglionic bowel?

It is now generally agreed that smooth muscle innervation is by an en-passant type of close approximation between axons containing vesicles and the muscle cells. Bennett and Rogers (1967) considered that a gap of $1,000 \AA$ in the taenia coli of guinea pigs would allow neuro-activation. In the present study numerous sites of close association were found in normal bowel and in distal aganglionic bowel and not infrequently the gap was $500 \AA$ or less. Thus it would seem that in the well innervated parts of Hirschsprung tissue neuro-effector sites do exist and there is some functional evidence in support of this. For example, uncoordinated contractions are often present in the aganglionic bowel and these can be stopped by low spinal anaesthesia (Ehrenpreis, 1946; Bodian, Stephens, and Ward, 1949). It would appear that even if nerves are preganglionic they sometimes achieve a functional relationship with the muscle cells.

Thus, as well as the deficiency of ganglia in Hirschsprung's disease, the pathology is influenced by the distribution of myenteric nerves which exhibit no obvious morphological abnormalities. Furthermore the deficiency of neuroeffector sites constantly found in the ganglionic bowel adjacent to the aganglionic segment suggests that this zone is capable of only reduced motor activity and radiological studies support this idea (Ehrenpreis, 1946; State, 1965).

We are indebted to $\mathrm{Mr} \mathrm{H}$. H. Nixon for the clinical material used in this study. We are also very grateful to Mr K. J. Davies, Miss M. Egan, and Miss M. Davidson for technical assistance.

During part of this study E.R.H. was assisted by an MRC grant.

\section{References}

Ambache, N., and Freeman, M. A. (1968). Atropine-resistant longitudinal muscle spasms due to excitation of noncholinergic neurones in Auerbach's plexus. J. Physiol., 199, 705-727. 
Bennett, A., Garrett, J. R., and Howard, E. R. (1968). Adrenergic myenteric nerves in Hirschsprung's disease. Brit. med. J., $1,487-489$.

Bennett, M. R., and Rogers, D. C. (1967). A study of the innervation of the taenia coli. J. cell. Biol., 33, 573-596.

Bodian, M. (1960). Pathological aids in the diagnosis and management of Hirschsprung's disease. In Recent Advances in Clinical Pathology, edited by S. C. Dyke. Series 3, pp. 385392. Churchill, London.

Bodian, M., Stephens, F. D., and Ward, B. C. H. (1949). Hirschsprung's disease and idiopathic megacolon. Lancet, 1, 6-11.

Ehrenpreis, T. (1946). Megacolon in the newborn. A clinical and roentgenological study with special regard to the pathogenesis. Acta chir. scand., 94, Suppl., 112.

Elfvin, L. G. (1963). The ultrastructure of the superior cervical sympathetic ganglion of the cat. 2: The structure of the preganglionic end fibers and the synapses as studied by serial sections. J. Ultrastruct. Res., 8, 441-476.

Garrett, J. R. (1966). The innervation of salivary glands. II. The ultrastructure of nerves in normal glands of the cat. J. roy. micr. Soc., 85, 149-162.

Garrett, J. R., Howard, E. R., and Nixon, H. H. (1969). Autonomic nerves in rectum and colon in Hirschsprung's disease. Arch. Dis. Childh., 44, 406-417.

Hökfelt, T. (1966). Electron microscopic observations on nerve terminals in the intrinsic muscles of the albino rat iris. Acta physiol. scand., 67, 255-256.

Hökfelt, T. (1967). Electron microscopic studies on brain slices from regions rich in catecholamine nerve terminals. Acto physiol. scand., 69, 119-120.
Kamijo, K., Hiatt, R. B., and Koelle, G. B. (1953). Congenital megacolon. A comparison of the spastic and hypertrophied segments with respect to cholinesterase activities, and sensitivities to acetylcholine, D.F.P. and the barium ion. Gastroenterology, 24, 173-185.

Karnovsky, M. J. (1965). A formaldehyde-glutaraldehyde fixative of high osmolality for use in electron microscopy. (Abstr.) J. cell. Biol., 27, 137-138A.

Kubozoe, T., Daikoku, S., and Takiti, S. (1969). Electronmicroscopic observations on Auerbach's plexus in a $12 \mathrm{~mm}$ human embryo. J. neurovisc. Relat., 31, 291-307.

Reynolds, E. S. (1963). The use of lead citrate at high $p \mathrm{H}$ as an electron-opaque stain in electron microscopy. J. cell. Biol., 17, 208-212.

Richardson, K. C. (1958). Electronmicroscopic observations on Auerbach's plexus in the rabbit, with special reference to the problem of smooth muscle innervation. Amer.J. Anat. $103,99-135$.

Richardson, K. C. (1966). Electronmicroscopic identification of autonomic nerve endings. Nature (Lond.), 210, 756.

Sabatini, D. D., Bensch, K., and Barrnnett, R. J. (1963). Cytochemistry and electronmicroscopy. The preservation of cellular ultrastructure and enzymatic activity by aldehyde fixation. J. cell. Biol., 17, 19-58.

Smith, B. (1970). Disorders of the myenteric plexus. Gut, 11, 271-274.

State, D. (1965). Rationale for segmental colon resection in the treatment of congenital megacolon (Hirschsprung's disease). In Current Surgical Management, III, edited by E. H. Ellison, S. R. Friesen, and J. H. Mulholland, pp. 427-433. Saunders, Philadelphia.

\section{(2)

